\title{
Survey of How Hanging Baskets Influence the Light Environment at Lower Crop Level in Ornamental Greenhouses in Ontario, Canada
}

\author{
David Llewellyn ${ }^{1}$, Youbin Zheng ${ }^{1,2,3}$, and Mike Dixon ${ }^{1}$
}

ADDITIONAL INDEX wORDS. DLI, light quality, light quantity, $P A R$, red to far red ratio, R:FR

SumMARY. Hanging basket (HB) production alters the light environment in the lower canopy of ornamental greenhouses by intercepting and altering the spectral quality of incoming light. If shading is sufficiently high, the quality of the lower crops can be reduced. This work investigated changes in light quantity and quality at the lower crop level caused by $\mathrm{HB}$ production in Ontario, Canada. Light sampling occurred at three commercial greenhouse facilities throughout the Spring $2012 \mathrm{HB}$ season. The greenhouses represented a range of $\mathrm{HB}$ densities $(1.8,2.4$, and 3.0 baskets $/ \mathrm{m}^{2}$ ) and different $\mathrm{HB}$ canopy architectures (one, two, and three tiers of HBs). Light samples were taken at three fixed locations within each greenhouse facility: outside, HB level, and lower crop level. Photosynthetically active radiation $(P A R)$ was logged continuously at each location within each greenhouse environment. Spectral scans were made at each sampling location, within each greenhouse facility, at various times throughout the season to assess how $\mathrm{HB}$ production altered the red to far red ratio (R:FR) at lower crop level. As the season progressed, outdoor daily light integrals (DLIs) more than doubled from $<20$ to $>40 \mathrm{~mol} \cdot \mathrm{m}^{-2} \cdot \mathrm{d}^{-1}$. Light reduction caused by polyethylene films and structural components varied among locations, but remained steady throughout the season, averaging $48.3 \%$ for the three locations. As the $\mathrm{HB}$ crops matured, the rate of decrease in $P A R$ at lower crop level varied according to facility and HB density with mean reductions of $42.5 \%, 32.6 \%$, and $37.7 \%$ for the one-, two-, and threetiered facilities, respectively. Mean lower crop level DLIs were all very similar, between 9.4 and $9.9 \mathrm{~mol} \cdot \mathrm{m}^{-2} \cdot \mathrm{d}^{-1}$. Accordingly, there may be insufficient light below HB canopies to produce high-quality crops of many varieties of bedding plants that are commonly grown in Ontario. The one- and two-tiered systems reduced the R:FR at lower crop level by $14 \%$ and $10 \%$, respectively, whereas the three-tiered system caused no reduction. More work is required to determine if the observed far red shift is sufficient to alter crop quality. These case studies provide a backdrop against which to help determine and interpret horticultural management strategies for a variety of greenhouse crops.

A $s$ in many other regions, Ontario's ornamental greenhouses often produce spring crops in more than one layer by placing one or more rows of $\mathrm{HBs}$ above the main crop growing on the greenhouse floor or bench (lower level). Although $\mathrm{HB}$ production maximizes the use of production area, shading at

This project was funded in part through Growing Forward, a federal-provincial-territorial initiative. The Agricultural Adaptation Council assists in the delivery of Growing Forward programs in Ontario.

We thank Waterloo Flowers, Greenway Blooming Center, and Jeffery's Greenhouses for providing access to their greenhouse production facilities for light sampling throughout the Spring 2012 hanging basket production season.

${ }^{1}$ School of Environmental Science, University of Guelph, 50 Stone Road East, Guelph, ON NIG 2Wl, Canada

${ }^{2}$ Vineland Research and Innovation Centre, 4890 Victoria Avenue North, Box 4000, Vineland Station, ON LOR 2E0, Canada

${ }^{3}$ Corresponding author. E-mail: yzheng@uoguelph.ca. the lower level by the HB crop may be a significant challenge to the production of high-quality plants. Shading by HBs logically reduces the quantity of light reaching the lower crop and may also alter its spectral quality through the preferential absorption/ transmission of specific wavelengths by the upper canopy. The combined effects may have both photosynthetic and photomorphological implications for the lower crops.

The designs of $\mathrm{HB}$ systems vary considerably, with positioning and density of HBs depending partially on greenhouse design (i.e., gutter heights, load-bearing capacity of the structure, and orientation) and largely on grower preferences. One-, two-, and three-tiered $\mathrm{HB}$ architectures are all commonly used with no clear distinctions as to the merits and drawbacks of each. In general, increasing the number of tiers also raises the production intensity by increasing $\mathrm{HB}$ density (number of HBs per square meter) and percent area coverage [square meters of $\mathrm{HBs} \div$ square meters of floor area (expressed as a percentage)]. What is not known is how $\mathrm{HB}$ production intensity affects the production of the lower level crops. Some Ontario floriculture growers have noted slower growth rates and decreases in crop quality (e.g., stretched internodes) when their main crop is produced under $\mathrm{HBs}$, but the specific causes and the magnitudes of their effects are unknown. It is common for plants grown below another plant canopy to have slower growth, longer times to maturity, stretched internodes, thin stems, reduced branching, and fewer flowers (Faust et al., 2005; Lopez and Runkle, 2008; Thomas, 2006). These effects are due, in part, to a reduction in the ratio of red to far red light caused by preferential absorption of red light by the upper plant canopy.

It has been postulated, by various growers, that reductions in plant quality when grown below $\mathrm{HB}$ crops are due to a combination of insufficient $P A R$ and reductions in the R:FR at the lower crop level. However, there are limited data available in peerreviewed literature, with none specific to Ontario, related to the shading effects caused by HBs in commercial greenhouses.

Photosynthetically active radiation is a quantification of photons within the photosynthetically active spectrum (i.e., 400 to $700 \mathrm{~nm}$ ) that are incident on a defined surface in a given period, usually measured in

\begin{tabular}{lllc}
\hline $\begin{array}{l}\text { Units } \\
\begin{array}{l}\text { To convert U.S. to SI, } \\
\text { multiply by }\end{array}\end{array}$ & U.S. unit & SI unit & $\begin{array}{l}\text { To convert SI to U.S., } \\
\text { multiply by }\end{array}$ \\
\hline 0.3048 & $\mathrm{ft}$ & $\mathrm{m}$ & 3.2808 \\
0.0929 & $\mathrm{ft}^{2}$ & $\mathrm{~m}^{2}$ & 10.7639 \\
6.4516 & inch $^{2}$ & $\mathrm{~cm}^{2}$ & 0.1550 \\
1 & micron & $\mu \mathrm{m}$ & 1 \\
1.6093 & mile(s) & $\mathrm{km}$ & 0.6214
\end{tabular}


micromoles of photons per square meter per second (Barnes et al., 1993). In greenhouse production, continuously recorded PAR measurements are integrated over each daylight period to form DLIs (moles of photons per square meter per day). DLI accounts for the temporal fluctuations in $P A R$ measurements, taken at fixed locations, due to variable weather patterns and changes in the sun's path across the sky (i.e., time of day and time of year). There is abundant literature describing the effects of DLIs on various aspects of production (e.g., propagation, vegetative growth, and flowering.) for numerous floriculture commodities (Wook et al., 2009). Korczynski et al. (2002) converted 30 years of absolute irradiance measurements from over 200 weather stations into DLI maps for the continental United States. Growers can use the maps to estimate the seasonal outdoor DLIs for their specific location and thus make informed cropping management decisions. There is no similar dataset available for Canada.

One of the ways that plants evaluate their light environment is by sensing the R:FR, where the wavelengths are absorbed by the pigment phytochrome. Since plants readily absorb red light (used in photosynthesis) but transmit or reflect far red light, the $\mathrm{R}: F R$ decreases within dense canopies or below an upper layer of foliage (e.g., a forest understory). The R:FR of ambient sunlight is generally between 1.0 and 1.2, although this varies considerably in the literature depending on location and how the ratio is calculated (Blom and Kerec, 2003; Clifford et al., 2004; Erwin et al., 2006; Feldhake and Glenn, 1997; Mata and Botto, 2009; Smith, 1982; Turnbull and Yates, 1993; Yamada et al., 2009; Yang et al.,
2012). When exposed to subambient $\mathrm{R}: \mathrm{FR}$, many common floriculture plants will shift their morphological development toward growing taller in an effort to access direct light. This is the so-called shade avoidance response and, in floriculture production, results in lower quality plants characterized by thinner stems, longer internodes, less branching, and fewer flowers (Blom et al., 1995; Fletcher et al., 2005; Runkle and Heins, 2001). It is not clear from the literature the magnitude of the decrease in R:FR needed to induce shade avoidance. This is likely due to the interaction of many varying factors including different species and cultivars, environmental parameters during production, specific lighting environments (e.g., natural vs. supplemental), and how various light characteristics are measured and reported.

A lighting survey was undertaken, during the Spring 2012 production season, to help characterize the influence of HBs on the light environment at the lower crop level in Ontario greenhouses. This survey comprised an extensive sampling regimen deployed in several production greenhouses representing the range of $\mathrm{HB}$ architectures typically used in this province.

\section{Materials and methods}

Three commercial greenhouse facilities in southern Ontario were selected, with the main differentiation being the number of tiers of HBs (one, two, and three) forming the overhead canopy. Ancillary differences (Table 1 ) between locations include the distance between the HBs and the lower crops (influenced by number of tiers, gutter heights, and bench vs. ground cultivation), the HB density (i.e., number of $\mathrm{HB}$ per square meter, influenced largely by grower preference and structural load-bearing considerations), and area coverage (i.e., the product of basket density and size of pots). The three-tiered greenhouse was oriented east-west. The one- and twotiered greenhouses were both oriented north-south.

Quantum sensors (SQ-110; Apogee Instruments, Logan, UT) were affixed to leveling plates and connected to data loggers (HOBO U-12; Onset Computer Corp., Bourne, MA). PAR data were collected continually (120-s intervals) at each facility from three specific locations: outside, above the HB canopy, and at lower crop level. Outdoor PAR sensors were mounted $0.7 \mathrm{~m}$ aboveground level and $5 \mathrm{~m}$ away from structures. Because the one- and two-tiered greenhouses were less than $0.9 \mathrm{~km}$ apart, the same outdoor PAR sensor (located at the onetiered greenhouse facility) was used for both locations. Inside sensors were mounted on $0.5-\mathrm{m}$ horizontal bars (providing adjustability in lateral positioning), which were subsequently affixed to gutter support posts just above the tops of HBs and lower crops, and which were angled at $45^{\circ}$ away from gutters, to reduce shading from adjacent structural components (i.e., gutters and collar ties). Two additional pairs of $P A R$ sensors were moved among the three greenhouse facilities, about every 5 to $7 \mathrm{~d}$, to verify the proper functionality and the data generated by the fixed sensors. PAR sampling began on 10 Mar., 28 Mar., and 5 Apr. 2012 in the one-, three-, and two-tiered greenhouses, respectively. PAR sampling ended on 16 May 2012 at the one-tiered greenhouse and 22 May 2012 at the two- and threetiered greenhouses. In total, 480,000 $P A R$ samples were taken from 21 locations (9 fixed and 12 roving) over

Table 1. Geographic location and characteristics of the three different hanging basket (HB) architectures surveyed.

\begin{tabular}{|c|c|c|c|c|c|}
\hline $\begin{array}{l}\text { Tiers of } \\
\text { HBs (no.) } \\
\end{array}$ & $\begin{array}{c}\text { Latitude } \\
\text { and longitude }\end{array}$ & $\begin{array}{c}\text { Distance between } \\
\text { upper and lower crops }(\mathrm{m})^{\mathrm{z}}\end{array}$ & $\begin{array}{c}\text { Distance between } \\
\text { adjacent rows of HBs }(m)^{y}\end{array}$ & $\begin{array}{l}\text { Canopy density } \\
\left(\text { baskets } / \mathrm{m}^{2}\right)^{\mathrm{y}}\end{array}$ & $\begin{array}{c}\text { Area coverage } \\
\text { of } \mathrm{HBs}(\%)^{\mathrm{x}}\end{array}$ \\
\hline 3 & $\begin{array}{l}43^{\circ} 9^{\prime} 18.22^{\prime \prime} \mathrm{N} \\
79^{\circ} 20^{\prime} 44.74^{\prime \prime} \mathrm{W}\end{array}$ & 2.4 & 4.2 & 3.0 & 22.2 \\
\hline 2 & $\begin{array}{l}43^{\circ} 29^{\prime} 57.41^{\prime \prime} \mathrm{N} \\
80^{\circ} 22^{\prime} 48.20^{\prime \prime} \mathrm{W}\end{array}$ & 1.7 & 4.5 & 2.4 & 16.4 \\
\hline 1 & $\begin{array}{l}43^{\circ} 30^{\prime} 17.08^{\prime \prime} \mathrm{N} \\
80^{\circ} 22^{\prime} 15.52^{\prime \prime} \mathrm{W}\end{array}$ & 0.9 & 3.0 & 1.8 & 9.1 \\
\hline
\end{tabular}

${ }^{\mathrm{z}} \mathrm{HB}$ architectures are differentiated by the number of distinct layers or tiers of HB sets located above the main crop's canopy.

${ }^{\mathrm{y}} \mathrm{l} \mathrm{m}=3.2808 \mathrm{ft}$, $\mathrm{l}$ basket $/ \mathrm{m}^{2}=0.0929$ basket $/ \mathrm{ft}^{2}$.

${ }^{x}$ Combined surface area of every HB pot located over a given floor area. 
$62 \mathrm{~d}$. These data were used to calculate 680 DLIs.

Weekly light quality assessments were made at each $P A R$ sensor location using a spectrometer (USB2000+; Ocean Optics, Dunedin, FL) with a $1.5-\mathrm{m}, 3900-\mu \mathrm{m}$-diameter ultravioletvisible optical fiber (300 to $800 \mathrm{~nm}$ ) tethered to a laptop running a SpectraSuite software package (Ocean Optics). All spectral scans occurred between 1100 and $1500 \mathrm{HR}$, with less than $\mathrm{lh}$ separating the scans of each site within a given greenhouse facility. Spectral assessments were made six times at the two-tiered and five times each at the one- and three-tiered greenhouses between 4 Apr. and 24 May 2012.

\section{Results and discussion}

Light QUANTITY. Figure 1 shows typical daily ambient outdoor $P A R$ measurements for clear (i.e., sunny), overcast (i.e., cloudy), and mixed (i.e., variable cloudiness) days. This graph shows the variability in instantaneous $P A R$ both throughout the normal course of a day and influence of varying weather. During the Spring 2012 season, the outdoor DLI varied between 5 and $50 \mathrm{~mol} \cdot \mathrm{m}^{-2} \cdot \mathrm{d}^{-1}$ (Fig. 2). Weather was the primary influence over this variability, especially through April. DLI increased linearly with time throughout the season. DLI roughly doubled from mid-March to mid-May, as the weather became increasingly sunny and the natural photoperiod increased.

There were too many confounding factors (e.g., greenhouse orientation, distance between HBs and lower crops, size and density of HB pots, and type of crop growing in HBs) to delineate a concrete relationship between the number of tiers of HBs and shading (Fig. 3). The two-tiered architecture provided consistently less shading over the lower crop than the one- and three-tiered systems. It is interesting to note that although the absolute amount of shading caused by HBs differed among the locations, shading at each location increased in a linear fashion throughout the season as the canopy of the $\mathrm{HB}$ crops increased in density (Fig. 3). The shading at the end of the $\mathrm{HB}$ season more than doubled for the two- and three-tiered locations from the beginning to the end of the sampling period, indicating that the foliage accounted for more than half of the

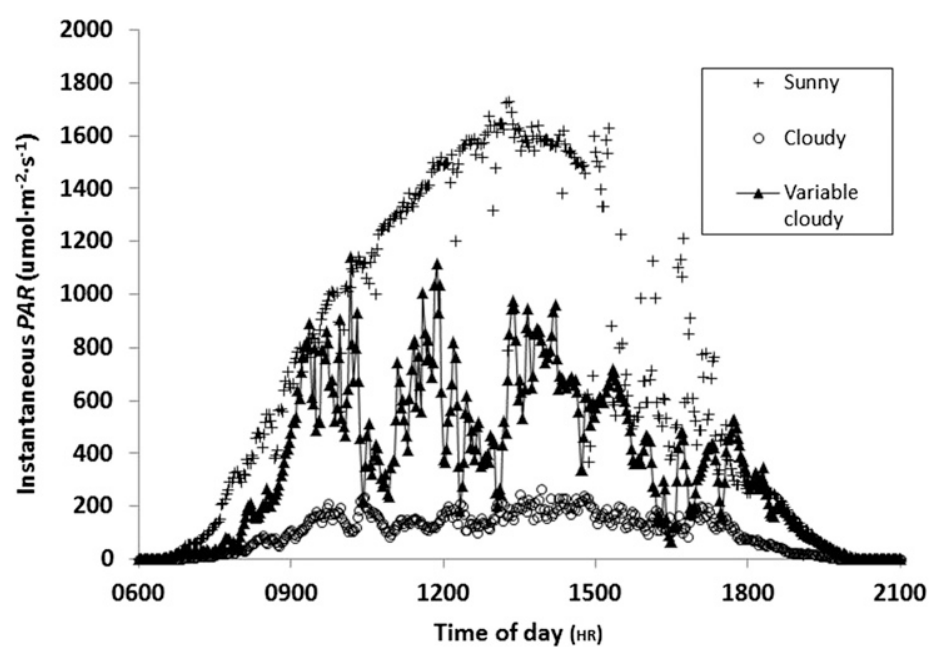

Fig. 1. Typical outdoor instantaneous photosynthetically active radiation (PAR) measurements for sunny (20 Apr.), cloudy (23 Apr.), and variably cloudy (24 Apr.) days during the Spring 2012 season. The daily light integrals (DLIs) for these days were $39.0,5.6$, and $19.5 \mathrm{~mol} \cdot \mathrm{m}^{-2} \cdot \mathrm{d}^{-1}$, respectively.

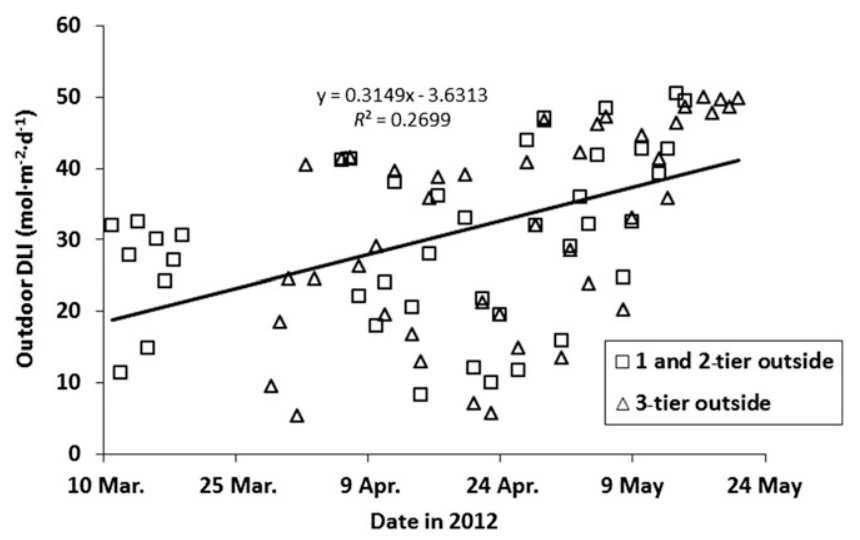

Fig. 2. Outdoor ambient daily light integral (DLI) from two locations in southern Ontario, Canada throughout the Spring 2012 season. The line is the best fit linear regression of the combined DLI data from both locations.

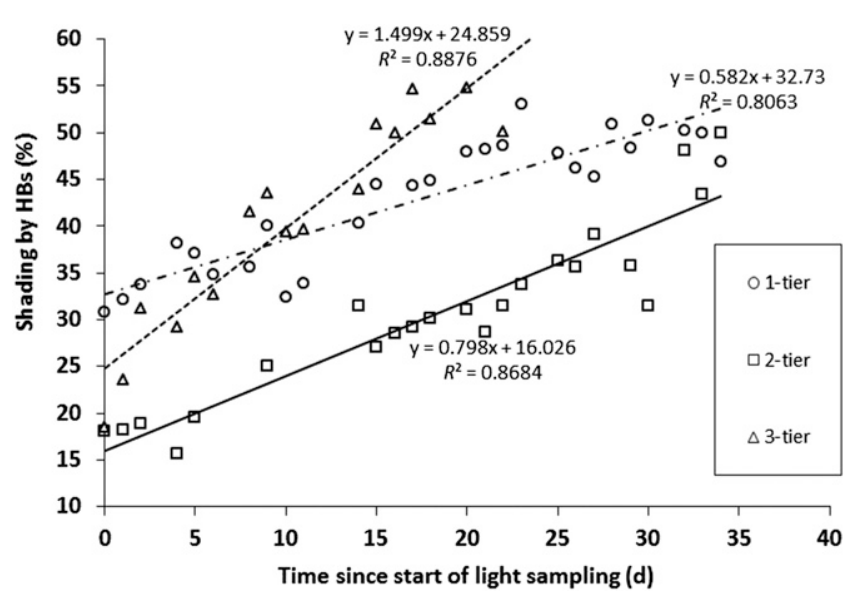

Fig. 3. Percent of photosynthetically active radiation $(P A R)$ reduction at lower crop level by the hanging basket (HB) crop during the Spring 2012 season for the three different $\mathrm{HB}$ canopy architectures. The lines represent the best fit linear regressions of the percent $P A R$ reduction at each respective location. 
total shading near the end of the season.

The DLI at HB level at the onetiered location was substantially higher than the other two greenhouse facilities over the season (Table 2 ). This was due, in part, to the age of the doublepolyethylene greenhouse covering, which was new at the one-tiered location and at least 3 years old at the other locations. Since transmissivity of polyethylene films reduces over time, primarily due to the photodegradation caused by ultraviolet light ( $\mathrm{Al}$ Ani and Anabtawi, 2012), growers are encouraged to follow the directions of the manufacturer with respect to frequency of replacement of their greenhouse coverings. Although there was considerable variability in light reductions at each location due to differences in transmissivity of glazing and shading from the $\mathrm{HBs}$, the interaction between these two factors resulted in highly comparable mean lower crop level DLIs for the three locations, ranging between 9.4 and $9.9 \mathrm{~mol} \cdot \mathrm{m}^{-2} \cdot \mathrm{d}^{-1}$. Moreover, there was an antagonistic relationship between the temporal increases in daily outdoor light intensity and the shading caused by the $\mathrm{HB}$ crop, which caused the DLI at lower crop level to remain fairly constant throughout the season (Fig. 4). The pattern was similar for all three locations.

Different species have different DLI requirements. The DLI recommendations for the main floriculture crops in North America are summarized in the Ball Redbook (Faust, 2001). Although the table in the Ball Redbook does not reference any specific literature, there is a large body of more recent studies investigating the DLI requirements of many floriculture crops including ageratum (Ageratum sp.), begonia (Begonia sp.), impatiens (Impatiens sp.), marigold (Tagetes sp.), petunia (Petunia sp.), sage (Salvia sp.), periwinkle (Vinca sp.), and zinnia (Zinnia sp.) (Faust et al., 2005); yarrow (Achillea sp.), guara (Guara sp.), and lavender (Lavandula sp.) (Fausey et al., 2005); gentian (Eustoma sp.) (Islam et al., 2005); geranium (Pelargonium sp.) (Loehrlein and Craig, 2004); and 41 herbaceous ornamental species (Mattson and Erwin, 2005). In general, DLI of at least $10 \mathrm{~mol} \cdot \mathrm{m}^{-2} \cdot \mathrm{d}^{-1}$ is required to produce high-quality crops. The average DLI for each greenhouse in this study was slightly under that threshold, with at least 10 $\mathrm{d}$ below $5 \mathrm{~mol} \cdot \mathrm{m}^{-2} \cdot \mathrm{d}^{-1}$ and only a few days during the whole season above $15 \mathrm{~mol} \cdot \mathrm{m}^{-2} \cdot \mathrm{d}^{-1}$.

There are no specific recommendations available for $\mathrm{HB}$ density in Ontario. Faust (2004), in his research highlight, suggests that $1.5 \mathrm{HB} / \mathrm{m}^{2}$ is a relatively high density; however, this value may not be commercially relevant in Ontario considering that the growers in the current study used HB densities ranging from 1.8 to 3.0 $\mathrm{HB} / \mathrm{m}^{2}$. This study has shown that high-intensity $\mathrm{HB}$ production may reduce lower crop level $P A R$ below the thresholds needed to produce high-quality floriculture crops in Ontario. Accordingly, growers should consider the DLI requirements for different lower level crops when selecting an $\mathrm{HB}$ system (i.e., HB density and number of tiers).

Light QUALITY. There is no agreed-upon convention in the scientific community for measuring and reporting R:FR. In particular, there are wide variations in specific wave bands and the units of measure used to calculate the ratio (Blom and Kerec, 2003; Capers and Chazdon, 2004; Clifford et al., 2004; Erwin et al., 2006; Feldhake and Glenn, 1997; Mata and Botto, 2009; Pecot et al., 2005; Turnbull and Yates, 1993; Yamada et al., 2009; Yang et al., 2012). When discussing this issue with various delegates at the 2012 International Symposium on Horticultural Lighting, it became clear that there

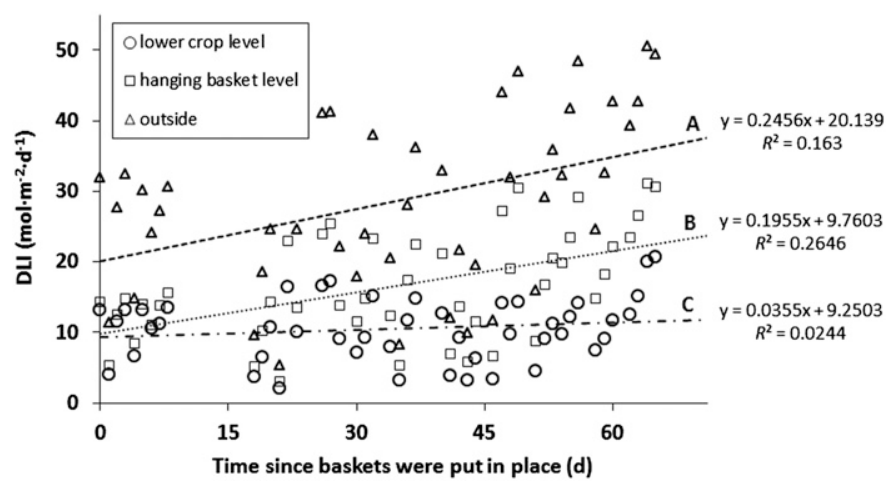

Fig. 4. Daily light integral (DLI) changes (A) outside, (B) at hanging basket level, and $(\mathrm{C})$ at lower crop level during the 2012 hanging basket season at the one-tiered facility. The lines represent the best fit linear regressions of the DLI at each respective sampling location within the facility.

Table 2. Daily light integral (DLI) and percent loss of photosynthetically active radiation (PAR) caused by different hanging basket $(\mathrm{HB})$ growing systems and polyethylene-film glazing during the Spring 2012 season. The growing systems are differentiated by the number of distinct layers or tiers of HBs located above the main crop's canopy within each greenhouse system.

\begin{tabular}{|c|c|c|c|c|c|c|c|}
\hline \multirow[b]{3}{*}{ Measure } & \multirow[b]{3}{*}{ Sampling location } & \multicolumn{6}{|c|}{ HB growing system ${ }^{z}$} \\
\hline & & \multicolumn{2}{|c|}{ One-tier } & \multicolumn{2}{|c|}{ Two-tier } & \multicolumn{2}{|c|}{ Three-tier } \\
\hline & & $($ mean $\pm S E)$ & $\bar{n}$ & $($ mean $\pm S E)$ & $n$ & $\overline{(\text { mean } \pm S E)}$ & $n$ \\
\hline & HB level & $17.4 \pm 1.35$ & & $14.3 \pm 1.16$ & & $13.6 \pm 1.18$ & \\
\hline & Lower crop level & $9.9 \pm 0.78$ & & $9.4 \pm 0.77$ & & $9.5 \pm 1.00$ & \\
\hline Loss of $P A R(\%)$ & Through polyethylene-film glazing & $40.1 \pm 0.61$ & & $50.7 \pm 1.05$ & & $54.1 \pm 0.96$ & \\
\hline
\end{tabular}

${ }^{2}$ Number of distinct layers of HBs. 
is a need for consensus among researchers in order for direct comparisons to be made in the literature. In the interim, it was advised that ratios of R:FR light be reported in both broad and narrow wave band formats, namely 600-700:700-800 and 655665:725-735 nm (E.S. Runkle, personal communication). It is also important to distinguish the units of measure since an intensity-based ratio will be biased toward a larger number than a photon-based ratio taken from the same light source. According to Smith (1982), intensity-based measurements can skew the R:FR by more than $10 \%$ of its value. Photon flux seems to be the more appropriate metric for generating R:FR since phytochrome conversion is related to the

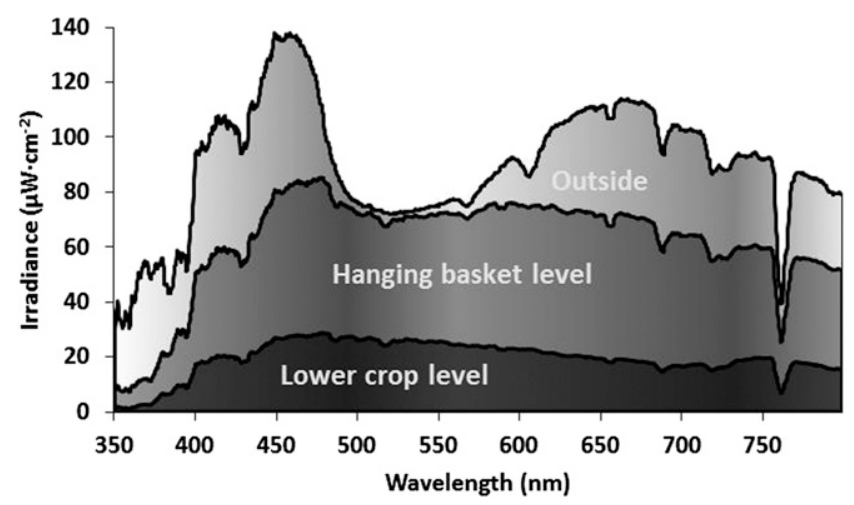

Fig. 5. Typical light spectra scanned at ambient, hanging basket, and lower crop levels. These scans were taken at the two-tiered greenhouse on 11 May 2012, which was a clear, sunny day; $1 \mu \mathrm{W} \cdot \mathrm{cm}^{-2}=6.4516 \mu \mathrm{W}$ inch $^{-2}$.

absorbance of discreet quantities of light, independent of the relative energies of the different wavelengths. Moreover, in some circumstances when reviewing the literature, it may be more appropriate to consider the relative changes in R:FR when comparing treatments. For this work, R:FR has been calculated using photon flux and has been reported for both the broad and narrow wave bands described earlier.

There were considerable differences in the spectral quality between HB level, lower crop level, and outside. Figure 5 shows typical light spectra taken from outside, HB level, and lower crop level. These scans were taken at the two-tiered greenhouse on 11 May 2012. Note the reductions in the blue and red wavelengths (400 to $500 \mathrm{~nm}$ and 600 to $700 \mathrm{~nm}$, respectively) between outside and inside the greenhouse structure. It would appear that the film covering this greenhouse modified the incoming light considerably, although the grower was unaware of using spectral-altering films.

Table 3. Calculations, using photon flux, of narrow (655-665:725-735 nm) and wide (600-700:700-800 nm) waveband red to far red ratio (R:FR) from the spectral scans taken within three hanging basket (HB) growing systems during the Spring 2012 season.

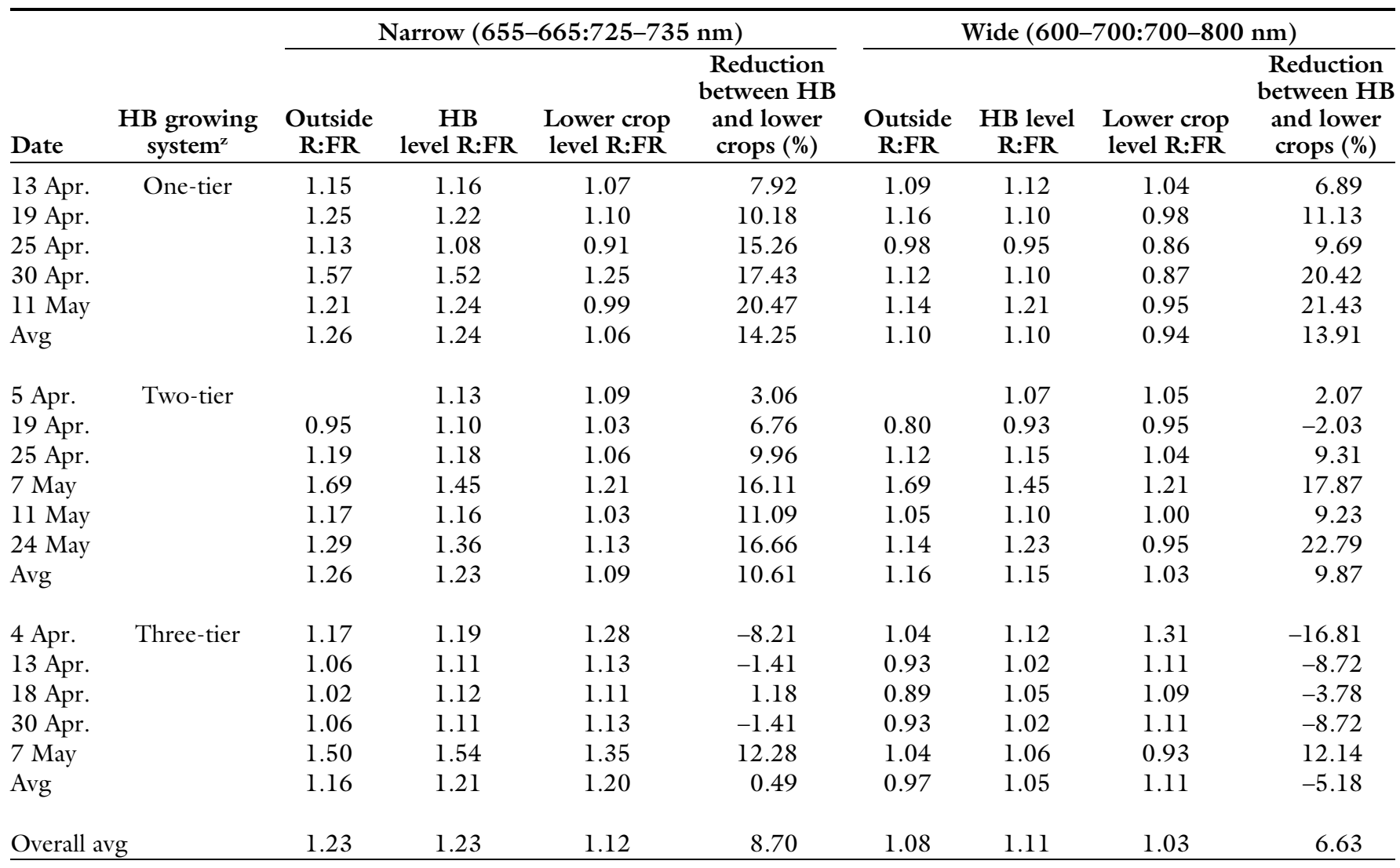

${ }^{\mathrm{z}}$ Number of distinct layers of HBs located above the main crop within each growing system. 
Also note that, when comparing $\mathrm{HB}$ and lower crop levels, the reduction in light from 600 to $700 \mathrm{~nm}$ is somewhat greater than the reduction in light from 700 to $800 \mathrm{~nm}$, resembling the predicted reduction in R:FR typically observed below a plant canopy.

Although every effort was made to have consistent lighting conditions between the different sampling locations within each facility on a given day, it should be stressed that the spectral scans were spot measurements and thus influenced by numerous, undefined confounding factors including time of day, fluctuations in outdoor weather, and differences in sensor positioning between sampling locations. Generally, the narrow band metric resulted in about $10 \%$ higher reductions in R:FR than the wide band metric in this study (Table 3 ). However, both metrics show similar relationships between the sampling locations at each greenhouse. In general, there was an inverse relationship between the number of tiers of HBs and the reduction in the R:FR between HBs at lower crop levels. The reason for this result is not readily apparent, although it is possible that the smaller distance between adjacent rows of HBs in the one-tiered facility (Table 1 ) resulted in a greater level of canopy closure. Since red light is preferentially absorbed by foliage vs. other wavelengths in the $P A R$ spectrum, a more uniform layer of foliage might have a larger relative reduction in $\mathrm{R}: \mathrm{FR}$ than the consequential reduction in PAR. In other words, even though the $\mathrm{HB}$ density is higher in the multitiered configurations, the lower tiers would be exposed to light that already had a relative reduction in the red wavelengths and thus would have a lesser impact over the absolute amount of red light reaching the lower crop levels.

The rate of reduction in the lower crop level R:FR (i.e., R:FR at lower crop level $\div$ R:FR at $\mathrm{HB}$ level), at each facility, rose in a linear fashion throughout the sampling period (Fig. 6). As the plants in the $\mathrm{HBs}$ increased in size, the upper foliage intercepted increasing amounts of red light. It was also observed, by varying the vertical positioning of the sensor head below the HB canopy, that R:FR reduced rapidly with increasing proximity to the bottom of the HB crops (Fig. 7). There is most likely a relatively

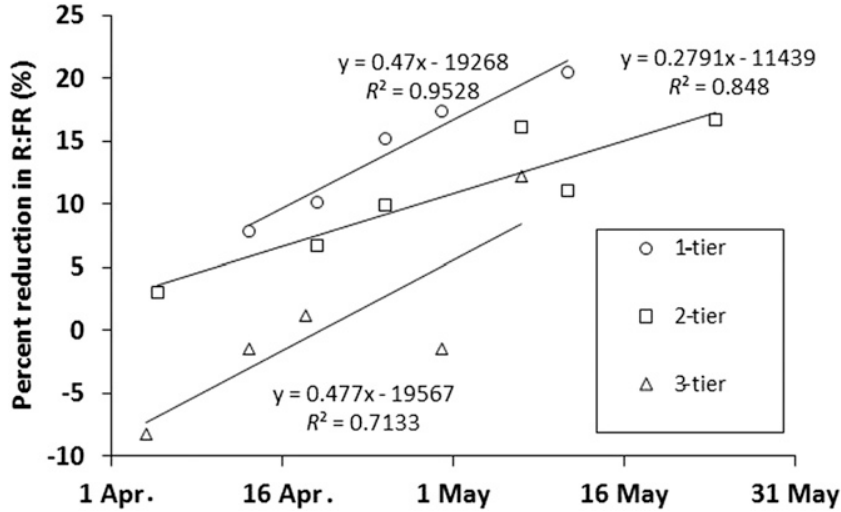

Fig. 6. The percentage reduction in red to far red ratio (R:FR) at lower crop level as the Spring 2012 hanging basket season progressed. The lines represent the best fit linear regressions of the percent R:FR reduction at lower crop level at each respective facility.

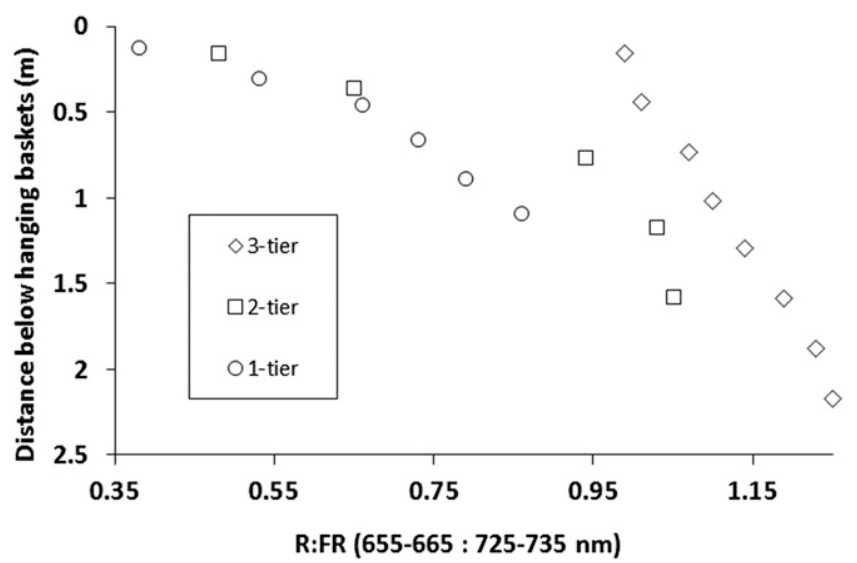

Fig. 7. Relationship between the lower crop level red to far red ratio (R:FR) and the distance between hanging basket and lower crops at each greenhouse facility; $1 \mathbf{~ m}=$ $3.2808 \mathrm{ft}$.

greater proportion of diffuse light (i.e., not filtered by foliage) reaching the sensor head with increasing distance below the HB canopy. This is due to the relatively low density of $\mathrm{HB}$ canopies [i.e., low leaf area index (LAI)] that are kept intentionally low to provide sufficient $P A R$ to the lower crops. This trend is in contrast to the observations of De Castro (2000) in a tropical rainforest (LAI about 7), where $\mathrm{R}: F R$ increased with height from the forest floor. For greenhouse HB production, it is recommended that every reasonable effort be made to maximize the distance between layers (e.g., switching from bench to floor culture) to minimize the potential far red shift at lower crop level.

It is unknown if the observed reductions in R:FR at lower crop level would be sufficient to induce shade avoidance responses to the common floriculture commodities that are typically grown under $\mathrm{HB}$ crops in Ontario. Because of the inconsistencies in the literature with respect to lighting conditions (i.e., natural vs. artificial) and how light quality is measured, it is impossible to draw any specific conclusions from this investigation. It is clear, however, that $\mathrm{HB}$ canopies in Ontario greenhouses have a substantial impact on the light quality reaching the lower crop level and this impact is magnified as the season progresses. Growers who have experienced shade avoidance responses in their lower crops are encouraged to reduce their $\mathrm{HB}$ densities or adjust the HB architecture toward multiple tiers, if space and infrastructure permits. Alternatively, supplementing the lower crop with red light during daylight periods when the R:FR is naturally low (i.e., during twilight hours at sunrise and 
sunset) (Smith 1982) is a promising application of newer light-emitting diode technologies, which may merit further investigation.

\section{Conclusion}

This study was undertaken to investigate the influences that $\mathrm{HB}$ production has on the lighting environment in Ontario greenhouses. The case studies described herein represent the range of $\mathrm{HB}$ production systems (i.e., gutter heights, number of tiers of $\mathrm{HBs}, \mathrm{HB}$ density, and $\mathrm{HB}$ area coverage) commonly found in Ontario's diverse floriculture industry. Although there was considerable variability in light alterations (i.e., quantity and quality) attributable to the various HB canopy architectures, all cases showed significant reductions in $P A R$ reaching lower crop levels. As outdoor DLI increased during the season (because of higher solar angles and longer photoperiods) so did the size of the plants in the HB canopy, resulting in relatively stable lower crop DLIs throughout the season. The R:FR at lower crop levels also generally reduced as the season progressed. These data serve as a benchmark for Ontario's floriculture industry and will serve to help growers and industry support representatives make informed decisions about multilayer production systems.

\section{Literature cited}

Al Ani, K.E. and M. Anabtawi. 2012. UVirradiation effect on the photodegradation of plasticized polyethylene (ortho, $\mathrm{m}$, and para-fluorostyrene) isomers in solid films. Intl. J. Chem. 4:62-84.

Barnes, C., T. Tibbitts, J. Sager, G. Deitzer, D. Bubenheim, G. Koerner, and B. Bugbee. 1993. Accuracy of quantum sensors measuring yield photon flux and photosynthetic photon flux. HortScience 28: 1197-1200.

Blom, T.J. and D.R. Kerec. 2003. Effects of far-red light/temperature DIF and farred light/temperature pulse combinations on height of lily hybrids. J. Hort. Sci. Biotechnol. 78:278-282.

Blom, T.J., M.J. Tsujita, and G.L. Roberts. 1995. Far-red at end of day and reduced irradiance affect plant height of Easter and
Asiatic hybrid lilies. HortScience 30:10091012.

Capers, R.S. and R.L. Chazdon. 2004. Rapid assessment of understory light availability in a wet tropical forest. Agr. For. Meteorol. 123:177-185.

Clifford, S.C., E.S. Runkle, F.A. Langton, A. Mead, S.A. Foster, S. Pearson, and R.D. Heins. 2004. Height control of poinsettia using photoselective filters. HortScience 39:383-387.

De Castro, F. 2000. Light spectral composition in a tropical forest: Measurements and model. Tree Physiol. 2000:49-56.

Erwin, J.E., C. Rohwer, and E. Gesick. 2006. Red:far red and photosynthetically active radiation filtering by leaves differs with species. Acta Hort. 711:195-200.

Fausey, B.A., R.D. Heins, and A.C. Cameron. 2005. Daily light integral affects flowering and quality of greenhousegrown Achillea, Gaura, and Lavandula. HortScience 40:114-118.

Faust, J. 2004. Research highlight: The effect of hanging baskets on the greenhouse light environment, p. 36. In: P. Fisher and E.S. Runkle (eds.). Lighting up profits: Understanding greenhouse lighting. Meister Media Worldwide, Willoughby, $\mathrm{OH}$.

Faust, J.E. 2001. Light, p. 71-84. In: D. Hamrick, (ed.). Ball redbook: Crop production. Ball Publishing, Batavia, IL.

Faust, J.E., V. Holcombe, N.C. Rajapakse, and D.R. Layne. 2005. The effect of daily light integral on bedding plant growth and flowering. HortScience 40:645-649.

Feldhake, C.M. and D.M. Glenn. 1997. Estimation of pasture drought severity using canopy red-to-far-red radiance. Environ. Expt. Bot. 38:81-86.

Fletcher, J.M., A. Tatsiopoulou, M. Mpezamihigo, J.G. Carew, R.G.C. Henbest, and P. Hadley. 2005. Far-red light filtering by plastic film, greenhousecladding materials: Effects on growth and flowering in petunia and impatiens. J. Hort. Sci. Biotechnol. 80:303-306.

Islam, N., G.G. Patil, and H.R. Gislerød. 2005. Effect of photoperiod and light integral on flowering and growth of Eustoma grandiflorum (Raf.) Shinn. Sci. Hort. 103: $441-451$.

Korczynski, P.M., J. Logan, and J.E. Faust. 2002. Mapping monthly distribution of daily light integrals across the contiguous United States. HortTechnology 12:12-16.

Loehrlein, M.M. and R. Craig. 2004. The effect of daily light integral on floral initiation of Pelargonium $\times$ domesticum L.H. Bailey. HortScience 39:529-532.

Lopez, R.G. and E.S. Runkle. 2008. Photosynthetic daily light integral during propagation influences rooting and growth of cuttings and subsequent development of new guinea impatiens and petunia. HortScience 43:2052-2059.

Mata, D.A. and J.F. Botto. 2009. Manipulation of light environment to produce high-quality poinsettia plants. HortScience 44:702-706.

Mattson, N.S. and J.E. Erwin. 2005. The impact of photoperiod and irradiance on flowering of several herbaceous ornamentals. HortScience 104:275-292.

Pecot, S.D., S.B. Horsley, M.A. Battaglia, and R.J. Mitchell. 2005. The influence of canopy, sky condition, and solar angle on light quality in a longleaf pine woodland. Can. J. For. Res. 35:1356-1366.

Runkle, E.S. and R.D. Heins. 2001. Specific functions of red, far red, and blue light in flowering and stem extension of long-day plants. J. Amer. Soc. Hort. Sci. 126:275-282.

Smith, H. 1982. Light quality, photoperception, and plant strategy. Annu. Rev. Plant Physiol. 33:481-518.

Thomas, B. 2006. Light signals and flowering. J. Expt. Bot. 57:3387-3393.

Turnbull, M.H. and D.J. Yates. 1993. Seasonal variation in the red/far-red ratio and photon flux density in an Australian sub-tropical rainforest. Agr. For. Meteorol. 64:111-127.

Wook, O., I.H. Cheon, K.S. Kim, and E.S. Runkle. 2009. Photosynthetic daily light integral influences flowering time and crop characteristics of Cyclamen persicum. HortScience 44:341-344.

Yamada, A., T. Tanigawa, T. Suyama, T. Matsuno, and T. Kunitake. 2009. Effects of red-light intensity during long-day treatment on flowering and cut flower quality in Eustoma grandiflorum cultivars for early-autumn shipment. Hort. Res. 8:309-314.

Yang, Z.Q., Y.X. Lil, X.D. Jiang, J. Zhu, and J.B. Zhang. 2012. Effects of different red to far-red radiation ratios on the senescence of greenhouse chrysanthemum leaves. African J. Agr. Res. 7:1919-1925. 